the development of the moniliasis. It is unfortunate that serum and cerebrospinal fluid penicillin levels were not estimated.

\section{Summary}

A case of bacterial endocarditis due to a highly resistant strain of Streptococcus faecalis is described. Although some measure of control of infection was obtained by a combined course of fucidic acid and penicillin the condition relapsed immediately the drugs were discontinued. Finally, the intravenous administration of penicillin in doses of 100 mega units daily for 3 months in conjunction with streptomycin and cephalosporin C for shorter periods brought about satisfactory resolution without complications.

\section{Acknowledgments}

I wish to thank Dr A. M. Ramsay for permission to publish details of this patient who was under his care. Thanks are also due to Professor R. S. Shooter for antibiotic assays and also to Beecham and Glaxo Laboratories.

\title{
Transradial dorsal perilunate fracture dislocation: an unusual fracture dislocation of the wrist joint
}

\author{
C. Galasko* \\ M.B., B.Ch.(W.Rand), F.R.C.S., F.R.C.S.E. \\ Registrar, Johannesburg General Hospital. \\ Department of Orthopaedics, University of Witwatersrand
}

INJURIES to the wrist are common. Fracture of the scaphoid, dislocation of the lunate and dorsal perilunate dislocation of the carpus are problems seen frequently in a busy Accident Service.

The combination of a dorsal perilunate fracturedislocation of the wrist and a fractured radial styloid is a very unusual injury. We have not been able to find a similar case in the literature and therefore feel that this case is worth reporting.

\section{Case report}

A 52-year-old male was involved in a car accident. He was concussed for a short while after the accident and was not able to describe the mechanism of the injury. He was admitted to an outlying hospital, where no radiologic service was available over week-ends. He was treated for shock and his injured wrist was immobilized in an above-elbow cast. He was transferred to the Johannesburg General Hospital 72 hr later when his general condition was satisfactory.

Radiological examination at this stage revealed an avulsion fracture of the second cervical spine, a compression fracture of the sixth cervical vertebra and roentgenograms, taken through plaster, showed the presence of an unreduced transradial dorsal perilunate fracture-dislocation of the wrist (Figs. 1 and 2). There was a dorsal perilunate dislocation with a fracture of the radial styloid, the small fragment maintaining its relationship to the scaphoid. The next day, $96 \mathrm{hr}$

*Present address: Hammersmith Hospital, London, W12.

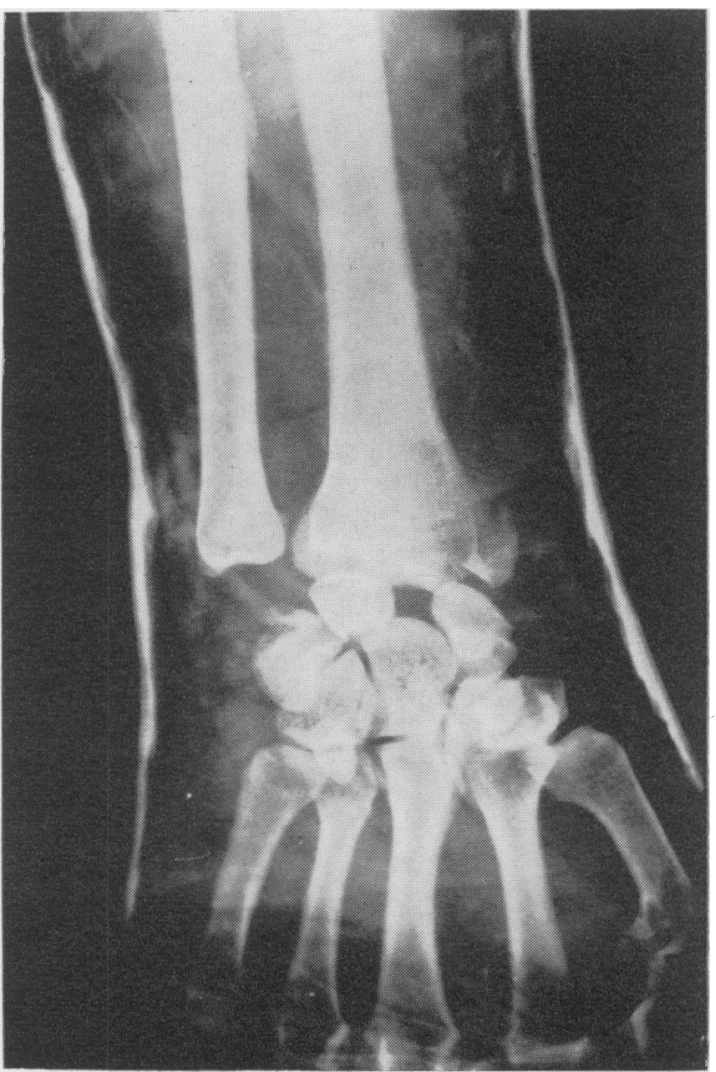

Fig. 1 . 


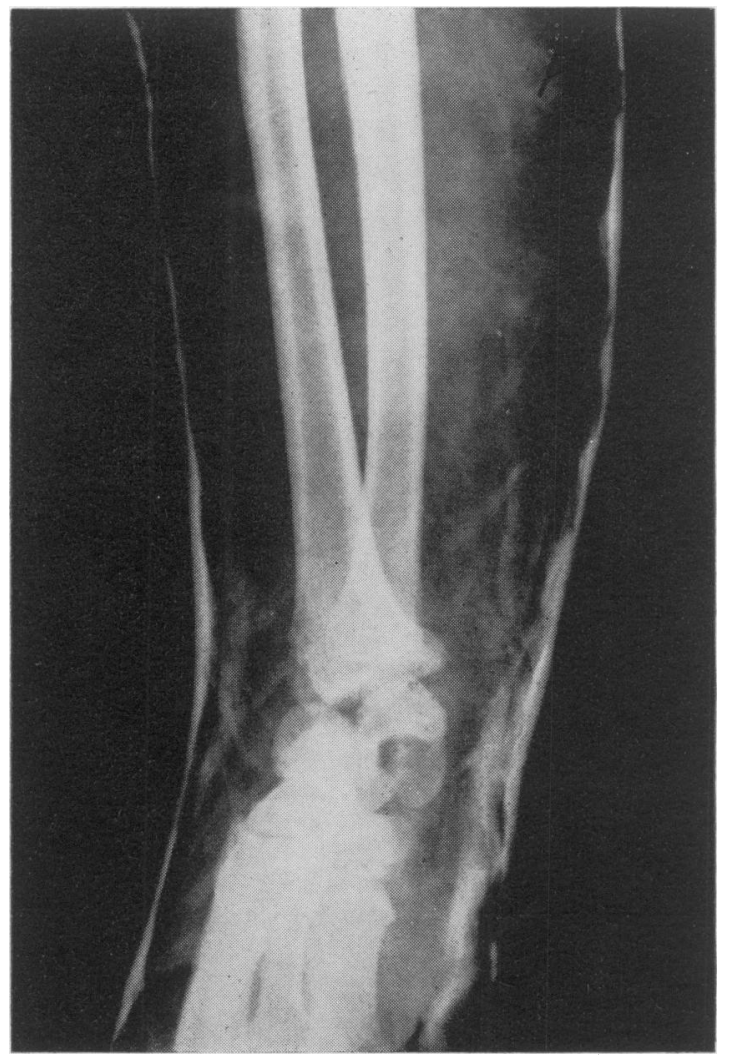

FIG. 2.

after the injury, the cast was removed and an attempt was made to reduce the dislocation, under a general anaesthetic.

It was impossible to reduce and maintain reduction in any position, and, as the skin under the plaster was not satisfactory for surgery, a new cast was applied and the anaesthetic discontinued. Any further attempts at treatment were precluded by the patient leaving hospital against instructions, and he has not been seen again.

\section{Discussion}

There are many classifications of wrist injuries but we were unable to find a similar case recorded in the literature. Speed (1942), in his book of fractures and dislocations around the wrist, mentions that trans-scaphoid perilunate dislocations and volar lunate dislocations may be complicated by a fracture of the radial or ulnar styloid or both. He does not, however, quote a case of the transradial perilunate fracture-dislocation.

The common dorsal perilunate fracture-dislocation is due to a fall on the outstretched hands, the wrist being extended and the hand being some distance away from the body (Aiken \& Natebuff, 1960).

A fall with the wrist extended and radially deviated causes the radial styloid to impinge on the scaphoid and may be responsible for the common association of fracture of radial styloid with a scaphoid fracture (Adler \& Shafton, 1962). It is possible, however, that with radial deviation the scaphoid, as it dislocates with the rest of the carpus, impinges upon the radial styloid and separates it from the rest of the radius, taking the fragment with it.

\section{Summary}

An unusual transradial dorsal perilunate dislocation of the wrist is described. The mechanism of fracture is postulated as being due to a fall on the outstretched hand, the wrist being extended and radially deviated and the hand being away from the body.

\section{Acknowledgments}

The author would like to thank the Superintendent of the Johannesburg General Hospital for permission to publish this case, $\mathrm{Mr} \mathrm{C}$. Moller under whose care the patient was admitted and $\mathrm{Mr}$ L. Solomon for reading through the manuscript.

\section{References}

Adler, J.B. \& Shafton, G.W. (1962) Fracture of the capitate. J. Bone Jt Surg. 44A, 1537.

Aiken, A.P. \& NATEBUfF, E.A. (1960) Volar transnavicular, perilunar dislocation of the carpus. J. Bone Jt Surg. 42A, 1051.

SPEED, K. (1942) Fractures and Dislocations, Chap. 16, p. 619. Lea \& Febiger, Philadelphia. 